\title{
Public/community Health Education Professional Accreditation among Stand- alone Baccalaureate Programs
}

\author{
Robert A. Chaney ${ }^{1}$, Kate Hendricks Thomas ${ }^{2}$, Randall Cottrell ${ }^{3}$, and David A. Birch ${ }^{4}$ \\ ${ }^{1}$ Brigham Young University, University of Cincinnati, Department of Health Science \\ ${ }^{2}$ Charleston Southern University, College of Health Sciences \\ ${ }^{3}$ University of North Carolina-Wilmington, School of Health and Applied Human Sciences \\ ${ }^{4}$ University of Alabama, Department of Health Science
}

\begin{abstract}
Background and Purpose: Formal training for health promotion practitioners often includes academic study in health education. Accreditation is an important quality assurance mechanism. One concern expressed during Council of Education for Public Health (CEPH) professional meetings is the capacity of stand-alone undergraduate programs in health education to meet the demands of accreditation. The purpose of this study was to determine the accreditation knowledge level among the program directors of stand-alone programs, and identify the perceived challenges, support for and value ascribed to accreditation among these programs operating without an affiliated graduate program. Methods: Thirtyfive undergraduate program coordinators identified via the 2009 American Association for Health Education (AAHE) directory completed a 21-item survey instrument. Results: Most program coordinators knew about undergraduate accreditation requirements (82.9\%), but program coordinators of self-identified small programs had significantly more concerns about the availability of resources needed to successfully attain accreditation. Conclusion: It is important to consider and provide resources for successful attainment of accreditation among smaller undergraduate institutions. Information regarding this general concern will be important to both the CEPH and academic program coordinators as they move forward with the new stand-alone baccalaureate accreditation initiative.
\end{abstract}

(C) 2015 Californian Journal of Health Promotion. All rights reserved.

Keywords: Health education; Undergraduate; CEPH; Accreditation; stand-alone programs

\section{Introduction}

Undergraduate and graduate programs in public/community health education play an important role in preparing health education professionals to collaborate effectively with community partners, corporate partners, and policymakers. Quality assurance metrics establish professional credibility and field standards for the contemporary health educator (Taub, Birch, Auld, Lysoby, \& King, 2009). The Council on Education for Public Health (CEPH) serves as the accrediting body for public/community health education programs at colleges and universities. Programs in public/community health education see accreditation as an indicator of program rigor, and undergraduate programs with an affiliated graduate program and graduate programs have established procedures in place for seeking accreditation. Beginning in 2014, CEPH began accepting accreditation applications from standalone baccalaureate programs that do not have an affiliated graduate program (CEPH, 2015). This study was conducted to gain more information related to stand-alone program accreditation issues and to determine program coordinators' knowledge, perceived challenges, support for, and value ascribed to accreditation.

\section{The National Task Forces on Accreditation in Health Education}

In 2001, the National Task Force on Accreditation in Health Education was formed 
to develop a detailed plan for a coordinated accreditation system in health education. Key principles emerging from task force collaboration were the common goals and responsibilities of various health education settings, and the importance of accreditation as a means of quality assurance in professional preparation. A 2004 report included a recommendation to expand CEPH accreditation to include undergraduate public health education programs (Allegrante et al., 2004). A second task force, the National Transition Task Force on Accreditation in Health Education, was formed in early 2004 and provided recommendations about accreditation in health education (including direction for programs preparing for accreditation and the anticipated timeline), provided support for health educator competencies, and developed plans to strengthen quality assurance in the profession over the next five years (Taub et al., 2009).

One frequently mentioned issue precipitated from the second task force concerned the capacity of stand-alone programs to meet the burden of accreditation requirements with respect to the resources required to be successful in this endeavor (Taub et al., 2009. A few years following, the third task force, National Implementation Task Force for Accreditation in Health Education (Implementation Task Force) was formed and conducted a study designed to determine the status and future plans for accreditation of stand-alone programs (i.e. not associated with a graduate or professional degree) in public/community health education and identify curricular and student issues. The study reported, “...the majority of undergraduate community health education programs planned to move forward when accreditation becomes available” (Miller, Birch \& Cottrell, 2010, p. 305).

Defining Small Programs. Distinguishing small programs from middle to larger-sized programs was believed to be important for this study, in terms of understanding different preparations for and needs for different programs to successfully obtain accreditation. The problem of defining "small" programs was evident here and has been cited in other studies
(Herbert, 2006; McGinnis, 1993). One study identified small programs as those having four or fewer faculty members, thirty or fewer majors, no affiliated graduate program, and low enrollments in upper division courses. Such programs were typically embedded in larger departments and dealt with the risk of being marginalized (Suson et al., 2008). Another clear definition was described as small programs being those that had three or fewer faculty members with no affiliated graduate program (Davidheiser \& Wolf, 2009).

For this study, directors of undergraduate programs that did not have an affiliated graduate program were contacted (Davidheiser \& Wolf, 2009; Susson, et al. 2009). The respondents were then asked if whether or not they identified their program as small. Thus, for this study, programs were considered "small" or "other" based on self-identification as a small program. The authors selected this method of program differentiation, as it was felt that perception of program size was more important than the actual size of the program when considering program accreditation.

\section{Methods}

\section{Participants}

Using the 2009 American Association for Health Education (AAHE) list of programs, the researchers selected only programs with no affiliated graduate program for participation for this study.

A total of 130 institutions on the AAHE list were identified and program coordinators received email solicitations to participate in the electronic survey. The researchers conducted web searches to find correct email addresses of program coordinators for "undeliverable" replies. Ultimately, updated web information could not be found for 20 programs coordinators which resulted in 110 program directors of health education undergraduate institutions who received an invitation to complete the survey.

In an effort to increase the response rate, a modification to the IRB proposal was submitted and approved, which allowed the researchers to conduct follow-up phone interviews with those 
who had not initially responded and those who could not be reached by email. The researchers called all 94 non-respondent program directors. All questions in the follow-up phone interview were identical to the initial electronic survey. Each of the 94 directors received two contact attempts on differing days and times in order to reach program directors.

The research team collected 29 electronic survey responses and completed 13 phone interviews, bringing the total number of respondents to 42 . Seven of the 42 respondents indicated they no longer had an undergraduate program; thus the total number of respondents who met eligibility criteria was 35 , representing a $28.5 \%$ response rate (35/123). For purposes of this analysis, size was determined by self-identified program size; $48.6 \%(n=17)$ self-identified as being a "small" program and $51.4 \%(n=18)$ self-identified as being "other" than small but still had no graduate program.

\section{Measures and Analyses}

A survey instrument focused on accreditation issues was developed by the authors and was reviewed by a panel of six experts with accreditation experience. This panel, recommended by Implementation Task Force members because of their experience with CEPH accreditation, included prior leaders of AAHE and the Society for Public Health Education (SOPHE), and university faculty at small and large institutions. The research team made appropriate modifications to the instrument based on the feedback received by this panel and from pilot testing. The final version of the survey consisted of 21 items- five closed-ended items and 16 open-ended items. The Institutional Review Boards for both the University of Alabama and the University of Cincinnati approved the survey and data collection procedures described here.

Because of the small non-random, sample, only descriptive data are presented for answers to all questions.

\section{Results}

\section{Knowledge of Accreditation}

The majority of coordinators had prior knowledge of undergraduate $\mathrm{CEPH}$ accreditation (82.9\%), but fewer small programs were familiar it compared to other programs (76.5\% vs. $82.9 \%)$. The majority (80\%) of all coordinators had intentions to seek accreditation, with smaller programs being less likely to seek accreditation (70.6\%) compared to other programs (88.9\%).

\section{Program Size}

The mean undergraduate enrollment among all participating programs was 92.3 students, with small programs reporting a much smaller mean enrollment compared to other programs $(\mathrm{M}=53$, $\mathrm{SD}=27.0)$ vs. $\mathrm{M}=131, \mathrm{SD}=71.1$ ). The overall average number of full-time faculty teaching was $4.6(\mathrm{SD}=2.5)$ and adjunct faculty was 3.4 $(\mathrm{SD}=4.0)$. Small programs had an average of 3.4 full-time faculty $(\mathrm{SD}=1.7)$ and 2.4 adjunct faculty $(S D=2.7)$ compared to other programs that had an average of 5.8 full-time faculty $(\mathrm{SD}=2.6)$ and 4.4 adjunct faculty $(\mathrm{SD}=4.8)$.

\section{Course Offerings}

The vast majority of programs offered courses that covered all NCHEC competencies (See Table 1).

\section{Accreditation Challenges and Strengths}

Financial resources (60.0\%) followed by data collection and tracking (37.1\%) were the most commonly cited challenges to accreditation whereas the most commonly cited strength was the capstone experience (See Table 2).

\section{Value of Accreditation}

Accreditation was generally perceived as valuable by program coordinators (See Table 3).

\section{Supporting Undergraduate Programs}

An open-ended question was included to address how the Accreditation Task Force could support undergraduate programs seeking accreditation. 
Table 1

Course Offerings and Instruction among Small Programs and Other Programs

\begin{tabular}{|c|c|c|c|c|c|c|}
\hline \multirow[b]{2}{*}{ Course } & \multicolumn{2}{|r|}{$\begin{array}{c}\text { Overall } \\
\mathrm{n}=18\end{array}$} & \multicolumn{2}{|c|}{$\begin{array}{c}\text { Small Programs } \\
\mathrm{n}=17\end{array}$} & \multicolumn{2}{|c|}{$\begin{array}{c}\text { Other programs } \\
\mathrm{n}=35\end{array}$} \\
\hline & $\begin{array}{c}\% \\
\text { Offered }\end{array}$ & $\begin{array}{c}\text { \% Taught by Dept. } \\
\text { Faculty }\end{array}$ & $\begin{array}{c}\% \\
\text { Offered }\end{array}$ & $\begin{array}{l}\text { \% Taught by Dept. } \\
\text { Faculty }\end{array}$ & $\begin{array}{c}\% \\
\text { Offered }\end{array}$ & $\begin{array}{l}\text { \% Taught by Dept. } \\
\text { Faculty }\end{array}$ \\
\hline Biostatistics & 71.4 & 60.0 & 82.4 & 64.7 & 61.1 & 55.6 \\
\hline Environmental Health & 91.4 & 80.0 & 94.1 & 82.4 & 88.9 & 77.8 \\
\hline Epidemiology & 94.3 & 91.4 & 94.1 & 88.2 & 94.4 & 94.4 \\
\hline $\begin{array}{l}\text { Health Services } \\
\text { Administration }\end{array}$ & 82.9 & 80.0 & 88.2 & 82.4 & 77.8 & 77.8 \\
\hline Social \& Behavioral Science & 97.1 & 91.4 & 100 & 82.4 & 94.4 & 100 \\
\hline
\end{tabular}

Table 2

Strengths and Challenges to Seeking Accreditation, Overall and by Self-Identified Size

\begin{tabular}{|c|c|c|c|c|c|c|c|c|c|c|c|c|}
\hline \multirow[b]{3}{*}{ Challenge } & \multicolumn{6}{|c|}{ Challenges to Accreditation } & \multicolumn{6}{|c|}{ Strengths for Accreditation } \\
\hline & \multicolumn{2}{|c|}{ Overall } & \multicolumn{2}{|c|}{ Small } & \multicolumn{2}{|c|}{ Other } & \multicolumn{2}{|c|}{ Overall } & \multicolumn{2}{|c|}{ Small } & \multicolumn{2}{|c|}{ Other } \\
\hline & $\mathrm{n}$ & $\%$ & $\mathrm{n}$ & $\%$ & $\mathrm{n}$ & $\%$ & $\mathrm{n}$ & $\%$ & $\mathrm{n}$ & $\%$ & $\mathrm{n}$ & $\%$ \\
\hline Financial resources & 21 & 60.0 & 12 & 34.3 & 9 & 25.7 & 4 & 11.4 & 0 & 0.0 & 4 & 11.4 \\
\hline Data collection \& tracking & 13 & 37.1 & 5 & 14.3 & 8 & 22.9 & 10 & 28.6 & 4 & 11.4 & 6 & 17.1 \\
\hline Curriculum change & 9 & 25.7 & 3 & 8.5 & 6 & 17.1 & 7 & 20.0 & 2 & 5.7 & 5 & 14.3 \\
\hline Admin. support & 9 & 25.7 & 7 & 20.0 & 2 & 5.7 & 16 & 45.7 & 6 & 17.1 & 10 & 28.6 \\
\hline Faculty support & 5 & 14.3 & 2 & 5.7 & 3 & 8.6 & 15 & 42.9 & 5 & 14.3 & 10 & 28.6 \\
\hline None & 2 & 5.7 & 0 & 0.0 & 2 & 5.7 & 0 & 0.0 & 0 & 0.0 & 0 & 0.0 \\
\hline Capstone experience & 0 & 0.0 & 0 & 0.0 & 0 & 0.0 & 21 & 60.0 & 8 & 22.9 & 13 & 37.1 \\
\hline
\end{tabular}

The most common responses were regarding the affordability/cost of accreditation ( $\mathrm{n}=5)$, clarity of accreditation requirements $(\mathrm{n}=5)$, and guidance via webinar or workshops toward accreditation $(n=4)$. A variety of other responses were observed as well: making the accreditation process flexible $(n=2)$, allow course curriculum integration versus stand-alone courses $(n=2)$, faculty resources $(\mathrm{n}=2)$, consistent CEPH/SABPAC collaboration $(\mathrm{n}=1)$, preparatory site visits $(\mathrm{n}=1)$, assistance

communicating the value added of accreditation to college administration $(n=1)$, curriculum development $(n=1)$, and continued dialogue with programs regarding accreditation $(n=1)$.

\section{Discussion}

We examined accreditation knowledge level of stand-alone program coordinators and identify the perceived challenges, support and value of accreditation among these programs. Programs generally perceive accreditation as being valuable but there are some areas of concern with respect to needs and barriers for small programs. Coordinators of stand-alone programs frequently stated that clear communication and support on the part of the Task Force regarding requirements for accreditation would be helpful to them. 
Table 3

Program Perceptions of the Value of Accreditation

\begin{tabular}{|c|c|c|c|}
\hline \multirow[b]{2}{*}{ Question } & \multicolumn{3}{|c|}{ Mean scores (SD.) ${ }^{\mathbf{a}}$} \\
\hline & $\begin{array}{l}\text { Overall } \\
(n=18)\end{array}$ & $\begin{array}{l}\text { Small } \\
(n=17)\end{array}$ & $\begin{array}{l}\text { Other } \\
(n=35)\end{array}$ \\
\hline $\begin{array}{l}\text { Accreditation will improve the reputation of our program on } \\
\text { campus. }\end{array}$ & $4.06(1.15)$ & $4.00(1.41)$ & $4.12(0.86)$ \\
\hline $\begin{array}{l}\text { Accreditation will improve the reputation of our program within the } \\
\text { community. }\end{array}$ & $4.03(1.14)$ & $3.94(1.39)$ & $4.12(0.86)$ \\
\hline $\begin{array}{l}\text { Accreditation will improve the reputation of our program within the } \\
\text { profession. }\end{array}$ & $4.06(1.10)$ & $4.00(1.32)$ & $4.12(0.86)$ \\
\hline $\begin{array}{l}\text { Accreditation will improve the marketability of our program to } \\
\text { prospective students. }\end{array}$ & $4.09(0.93)$ & $4.27(0.88)$ & $3.94(0.97)$ \\
\hline $\begin{array}{l}\text { Accreditation will improve the marketability of our students upon } \\
\text { graduation. }\end{array}$ & $3.88(0.87)$ & $4.00(0.93)$ & $3.77(0.83)$ \\
\hline $\begin{array}{l}\text { Our program faculty supports accreditation of our undergraduate } \\
\text { public/community health education program. }\end{array}$ & $4.12(1.05)$ & $4.00(1.32)$ & $4.25(0.68)$ \\
\hline $\begin{array}{l}\text { Our university administration supports accreditation of professional } \\
\text { preparation programs. }\end{array}$ & $4.09(1.07)$ & $3.94(1.35)$ & $4.25(0.68)$ \\
\hline
\end{tabular}

a. Scores were based on a 5-point Likert scale: 1=strongly disagree, $2=$ disagree, $3=$ =neutral, 4=agree, $5=$ strongly agree.

One potential barrier for small programs in particular is course offerings. Our findings suggest that small programs particularly struggled to offer a course in biostatistics and health services administration. The finding that more small-program courses are taught by department faculty may suggest these programs have fewer interdepartmental resources to aid in curricular support or change needed for accreditation, or that they have the resources to meet course teaching needs. In response to these findings, it will be important for CEPH and the National Implementation Task Force to inform small programs that critical component elements (CCEs) do not require any specific courses to be included in the curriculum, but can be met by a variety of courses both within and outside the major courses, thus providing flexibility for small programs.

The most common challenges to accreditation indicated were finances and data collection/tracking. A larger proportion of small program coordinators also saw administrative support as being a real challenge to seeking accreditation. Small program coordinators need to determine what sources of funding are available at their institution for program accreditation. Often accreditation costs are covered at the college or university level and do not come out of program budgets. Programs coordinators should discuss accreditation with other accredited campus programs to determine how accreditation costs were covered. Advocating for administrative support, small programs can emphasize that in the near future, NCHEC will require graduates sitting for the CHES exam to come from accredited programs (Taub, et al., 2009).

The perceived value of accreditation was generally high. Responses indicated that standalone programs with small faculty teams and limited resources could be supported in accreditation if CEPH makes the process affordable and outlines clearly-articulated requirements.

\section{Limitations}

There were inherent limitations to this study. First, data were collected via online and telephone surveys, which may have resulted in some degree of self-report bias. Second, participants were only selected from the AAHE directory. Programs that were not in the directory were not solicited to participate in the study.

\section{Conclusion}

This study indicates that a strong commitment to quality training already exists in the majority of 
coordinators responding and there is interest in seeking accreditation. The results of this study should encourage $\mathrm{CEPH}$ and the professional associations to assist smaller programs to determine the feasibility of program accreditation and explore alternative ways of covering the CCEs.

\section{Acknowledgements}

We would like to thank the panel of experts who reviewed the survey instrument for their feedback and support in this endeavor. We also acknowledge and express thanks to Elaine Auld for involvement in conversations early in the conception of this project. We gratefully acknowledge the time and efforts of the reviews for this manuscript.

\section{References}

Allegrante, J. P., Airhihenbuwa, C. O., Auld, M. E., Birch, D. A., Roe, K. M., Smith, B. J., \& National Task Force on Accreditation in Health Education. (2004). Toward a unified system of accreditation for professional preparation in health education: Final report of the National Task Force on accreditation in health education. Health Education \& Behavior, 31(6), 668-683.

Council on Education for Public Health. (n.d.). Standalone baccalaureate programs. Retrieved July 1, 2015, from www.ceph.org

Davidheiser, J., \& Wolf, G. (2009). Fanning the flames: Best practices for ensuring the survival of small German programs. Die Unterrichtspraxis/Teaching German, 42(1), 60-67.

Herbert, J. T. (2006). Accreditation options for the undergraduate rehabilitation program. Rehabilitation Education, 20(3), 179-190.

McGinnis, H. K. (1993). The status of small MPA programs: A commitment to quality, diversity, and uniqueness. International Journal of Public Administration, 16(1), 15-33.

Suson, D. J., Cox, P. H., Hewett, L. D., Leckenby, H. J., Espinosa, J., Fisher, P., ... Willson, V. L. (2008). Distributed departments: A new approach to protecting the vitality of small programs. Journal of Science Education and Technology, 17(6), 595-609.

Taub, A., Birch, D. A., Auld, M. E., Lysoby, L., \& King, L. R. (2009). Strengthening quality assurance in health education: Recent milestones and future directions. Health Promotion Practice, 10(2), 192-200.

Author Information

*Robert A. Chaney

Brigham Young University, 3104 Life Sciences

Building, Provo UT, 84602; (email) rchaney@byu.edu; (phone) 801/422-0658.

* corresponding author 